\section{Paternal psychopathology and maternal depressive symptom trajectory during the first year postpartum}

\author{
Kimberly L. D'Anna-Hernandez,1 \\ Gary O. Zerbe, ${ }^{2}$ Sharon K. Hunter, 1 \\ Randal G. Ross 1 \\ 1Department of Psychiatry, University of \\ Colorado Denver, Aurora, CO; \\ 2Department of Biostatistics \& \\ Informatics, Colorado School of Public \\ Health, University of Colorado Denver, \\ Aurora, CO, USA
}

\section{Abstract}

Understanding parental psychopathology interaction is important in preventing negative family outcomes. This study investigated the effect of paternal psychiatric history on maternal depressive symptom trajectory from birth to 12 months postpartum. Maternal Edinburgh Postpartum Depression screens were collected at 1, 6 and 12 months and fathers' psychiatric diagnoses were assessed with the Structured Clinical Interview for DSM-IV from 64 families. There was not a significant difference in the trajectory of maternal depressive symptoms between mothers with partners with history of or a current psychiatric condition or those without a condition. However, mothers with partners with substance abuse history had higher levels of depressive symptoms relative to those affected by mood/anxiety disorders or those without a disorder. Our results call for a closer look at paternal history of substance abuse when treating postpartum maternal depression.

\section{Introduction}

Depression is a serious illness that contributes to overall poor health. Women are especially at risk of developing depression during pregnancy and in the postpartum period, 1 which often results in decreased maternal well-being and a dysregulation of maternal behavior. ${ }^{2}$ The etiologic explanation underlying the temporal relationship between the postpartum period and increased risk for depression is not completely understood; most of the research efforts have focused on issues internal to the postpartum woman, such as alterations in maternal hormones or changes in role expectations. ${ }^{3-5}$ Much less effort has been placed on understanding the role of the father and the complex interplay between maternal and paternal mental health. ${ }^{6-8}$ This study aims to understand the role of paternal psychiatric history on the trajectory of maternal depressive symptoms during the first postpartum year.

The role of fathers in the postpartum period is important as fathers can provide part of the mothers' network of social support by sharing in parental duties and helping with the transition into motherhood. ${ }^{9}$ Lack of adequate social support tends to lengthen the distress caused by an episode of general depression. ${ }^{10,11}$ During both pregnancy and the postpartum period difficulties with social support are associated with greater symptoms of maternal depression.12,13 The relationship between the woman and her partner has been shown to have the most significant impact on maternal depression prenatally. ${ }^{12}$ In addition, absent fathers, though interested, might not pursue a relationship with their children because of societal attitudes and stereotypes that discourage paternal involvement.6,14 This may generalize into the post-partum period, especially during the first year, as failure of fathers to provide support may increase severity and duration of a maternal depressive episode.

The birth of a child is also a major life event for fathers, as evidenced by the two-fold increase in paternal psychopathology in the postnatal period.7,15 Thus, fathers with psychopathology may exhibit impaired ability to support mothers. Fathers who do not currently have mental health symptoms, but have a history of psychiatric illness are at risk for reoccurrence and may also respond to the birth of a child by withdrawing support. Fathering may also be impaired by paternal depression and possibly other types of psychopathology. Father psychopathology can exacerbate the negative effects of a mother's depressive symptoms on offspring in some, ${ }^{16,17}$ but not all studies. ${ }^{18}$ Thus, fathers both with and at-risk for psychopathology may influence the severity of depressive symptoms of the mother.

This study assesses whether the trajectory of maternal postpartum depressive symptoms is associated with the presence or lack of paternal risk for psychopathology. We hypothesize that mothers with partners who have a history of a psychiatric history will have an increased trajectory of maternal depressive symptoms overtime, regardless of their own depressive history. This study extends previous work by investigating how other types of paternal psychopathology, in addition to paternal depression, directly influence maternal depressive symptoms over the first year postpartum.
Correspondence: Kimberly L. D’Anna-Hernandez, Department of Psychology, 333 S. Twin Oaks Valley Rd, San Marcos, CA, USA.

Tel. +1.760 .7508275 - Fax: +1.760 .7503418$

E-mail: kdanna@csusm.edu

Key words: postpartum depression, paternal substance abuse, fathers, motherhood.

Acknowledgements: the authors thank the families who participated in this research and Julie Beuler, Kate Hanna, Kimberly Muhlhauser, Alexandria Newton and Shauna Goldberg whose quality efforts were critical for data collection. This work was supported by an institutional $\mathrm{NIH}$ NRSA postdoctoral research training program, MH015442, a NSF Minority Postdoctoral Research Fellowship to Dr. Kimberly D'Anna and the National Institute of Mental Health Grants MH56539 and MH086383.

Contributions: KDH, RR, SH, made substantial contributions to the conception, design, acquisition and interpretation of the data; $\mathrm{KDH}, \mathrm{GZ}$, made significant contributions to the analysis and interpretation of the data; all authors were involved in drafting and revising the article critically for important intellectual content and gave approval of the final version of this manuscript prior to publication.

Conflict of interests: the authors declares no potential conflict of interests.

Received for publication: 29 September 2012. Revision received: 22 0ctober 2012.

Accepted for publication: 22 October 2012.

This work is licensed under a Creative Commons Attribution NonCommercial 3.0 License (CC BYNC 3.0).

CC Copyright K.L. D'Anna-Hernandez et al., 2013

Licensee PAGEPress, Italy

Mental Illness 2013; 5:e1

doi:10.4081/mi.2013.e1

\section{Materials and Methods}

\section{Sample}

Participants were followed longitudinally from birth through the child's first birthday as part of a larger study on focusing on the impact of prenatal factors on offspring risk for mental illness for a total of 64 families. A power analysis determined adequate power such that a sample size of 64 has $80 \%$ power to detect an $r^{2}=0.30$ (a medium effect size) attributed to an independent variable using an F-Test with $=0.05$. All procedures followed were in accordance with the ethical standards of the responsible committee on human experimentation (institutional and national) and with the Helsinki Declaration of 1975, (as revised in 2008). All studies were reviewed, approved and 
conducted in compliance with by the Colorado Multiple Institutional Review Board. All research subjects provided informed consent prior to the inclusion in the study.

Recruitment into the current study was completed via two methods. First, using a state birth registry, women who recently birthed a child and resided in the greater Denver metropolitan region were contacted via mail soliciting interest in research projects. Interested women who returned a stamped postcard were contacted to provide additional information. This method recruited 36 women. This sample was also supplemented by pregnant women who were recruited by staff at a local county hospital. This method recruited 25 participants. The subjects and their infant offspring were recruited as part of a larger longitudinal study examining the impact of various prenatal maternal factors on infant's markers of risk for psychiatric illness. Three participants contacted our study personnel directly. While time of recruitment varied (pre $v s$. postnatal), and all study variables were collected postpartum and all postpartum study procedures were identical

Additionally, there no demographic differences or differences in the psychiatric history between women recruited in pregnancy $v$ s. the postpartum period (data not shown), thus all women were analyzed as a complete data set. Participants came to the laboratory at 1, 6 and 12 months postpartum with their infants. At these time points parents filled out various questionnaires for parental stress and depression as well as participated in infant assess-
Table 1. Number of fathers in each diagnostic category $(n=30)$.

\begin{tabular}{lcc} 
Paternal diagnoses & N & $\%$ \\
Substance abuse & 10 & 32.3 \\
Anxiety disorders & 3 & 9.7 \\
\hline Mood disorders & 9 & 29.0 \\
Psychosis & 1 & 3.2 \\
\hline Comorbid-mood/substance abuse & 8 & 25.8 \\
\hline
\end{tabular}

Table 2. Parental characteristics.

\begin{tabular}{|c|c|c|c|c|}
\hline \multirow[t]{2}{*}{ Characteristics } & \multicolumn{2}{|c|}{ Maternal } & \multicolumn{2}{|c|}{ Paternal } \\
\hline & N & $\%$ & $\mathbf{N}$ & $\%$ \\
\hline \multicolumn{5}{|l|}{ Age } \\
\hline $18-19$ & 4 & 6.2 & 3 & 4.7 \\
\hline $20-29$ & 30 & 46.9 & 32 & 50.0 \\
\hline $30-39$ & 28 & 43.8 & 26 & 40.6 \\
\hline $40-45$ & 2 & 3.1 & 3 & 4.7 \\
\hline \multicolumn{5}{|l|}{ Race/ethnicity } \\
\hline Caucasian non-hispanic/latino & 37 & 57.8 & 30 & 46.9 \\
\hline Hispanic/latino & 18 & 28.1 & 26 & 40.6 \\
\hline African-american & 6 & 9.4 & 6 & 9.4 \\
\hline Mixed/other & 3 & 4.7 & 2 & 3.1 \\
\hline \multicolumn{5}{|l|}{ Employment status } \\
\hline Unemployed & 28 & 43.7 & 54 & 84.5 \\
\hline Part-time & 14 & 21.9 & 1 & 1.6 \\
\hline Full-time & 21 & 32.8 & 8 & 12.5 \\
\hline Unknown & 1 & 1.6 & 1 & 1.6 \\
\hline \multicolumn{5}{|l|}{ Years of education } \\
\hline$<12$ & 6 & 9.4 & 8 & 12.5 \\
\hline 12 & 22 & 34.4 & 27 & 42.2 \\
\hline$>12$ & 36 & 56.2 & 28 & 43.7 \\
\hline Unknown & 0 & 0 & 1 & 1.6 \\
\hline \multicolumn{5}{|l|}{ Marital status } \\
\hline Married & 42 & 65.6 & & \\
\hline Living together, not married & 19 & 29.7 & & \\
\hline Not living together, not married & 3 & 4.7 & & \\
\hline
\end{tabular}

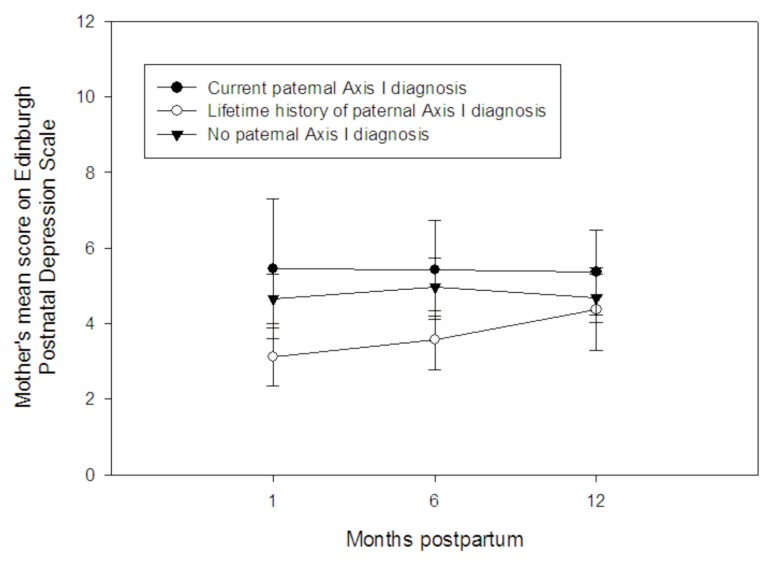

Figure 1. Relationship between lifetime history and current diagnosis of paternal mental health and maternal depressive symptoms during the first year postpartum. There was no significant difference $(\mathbf{P}=0.09)$ in maternal depressive symptom trajectory between mothers where child's father did not receive an Axis I diagnosis relative to mothers where child's father demonstrated a lifetime history an Axis I diagnosis $(n=31)$. There also was no difference in maternal depressive symptom trajectory between mothers where child's father demonstrated a current history an Axis I diagnosis relative to mothers with a where child's father had a lifetime Axis I diagnosis or to mothers with a where child's father did not have a Axis I diagnosis.. Bars represent means \pm SEM.

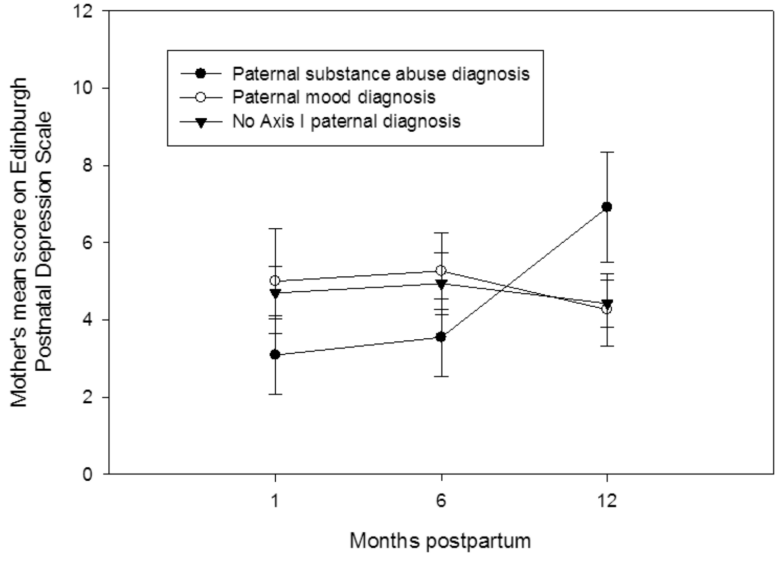

Figure 2. Relationship between history of paternal mental health diagnosis (none vs. substance abuse vs. mood-related) and maternal depressive symptoms during the first year postpartum. Mothers where child's father demonstrated a history of an Axis I diagnosis of substance abuse had an overall increasing trajectory of elevated depression symptom means relative to mothers where child's father had history of a mood-related disorder $(P=0.02)$ or did not have a paternal diagnosis $(P=0.01)$. However, there was no difference between mothers where child's father had history of a mood-related disorder or did not receive an Axis I diagnosis. Bars represent means \pm SEM. ${ }^{*} \mathrm{P}<\mathbf{0 . 0 5}$ 
ment of development. Mothers and fathers also came once during this first 12 months to participate in a psychiatric interview. As this study is interested in whether the presence or lack of paternal risk for psychopathology affects the trajectory of maternal postpartum depressive symptoms during the first year postpartum, only participants with postnatal depressive symptom assessments at 1, 6 and 12 months and who were paired with fathers that participated in the psychiatric interview are included in this analysis. The sample from the current study did not differ on any demographic variables from the larger sample it was derived from (data not shown).

\section{Maternal depressive symptomology}

The Edinburgh Postnatal Depression Scale (EPDS), ${ }^{19}$ a widely used 10 -item self report questionnaire, was administered to assess maternal depressive symptoms in the postpartum period. The mother was asked to choose the response that came closest to how she had been feeling in the previous 7 days. The responses were scored on scale of 0-3 with a minimum total score of 0 and a maximum score of 30 . Those women who scored 13 and above were considered to be at high risk of experiencing depressive symptoms and is often the level used to evaluate clinical depression. ${ }^{19,20}$ The EPDS is widely used with a splithalf reliability of 0.88 , and an internal consistency coefficient of 0.87 .21 This measure is effective in detecting depressive symptoms both pre and postnatally, ${ }^{21}$ and within diverse populations.21-23 The severity of maternal mood and depressive symptoms was evaluated during 1,6 and 12 months postpartum.

\section{Father risk for mental illness}

The greatest predictor of risk for future psychiatric illness is a history of psychiatric illness. To obtain this lifetime and current history, the biological father underwent a Structured Clinical Interview for DSM-IV (SCID) administered by a clinically-licensed social worker with post-masters fellowship training in outpatient psychiatric care. The SCID is a semi-structured clinical interview used to collect alcohol/drug abuse and psychiatric history and current symptoms. Using the information gathered in the SCID, the father was given a diagnosis if they met criteria for an Axis I diagnosis at any time during their life; diagnoses were best-estimate diagnoses, defined as final diagnoses determined after review of all the clinical data obtained in the SCID. Thirty-one of the 64 fathers evaluated reached criteria for at least one Axis I diagnosis. The paternal diagnoses collected are listed in Table 1. Only one of the fathers exhibited psychosis, thus it was not included in the analysis. Sixteen fathers met criteria for a lifetime diagnosis, while 14 fathers met criteria

Table 3. Maternal depression characteristics at 1, 6 and 12 months postpartum. $\%$ clinical refers to the percentage of mothers whose Edinburgh score were $\geq 13$.

\begin{tabular}{lccccc} 
Time points & Mean & Std error & Min & Max & \% clinical \\
1 month & 4.4 & 0.6 & 0 & 21 & 4.7 \\
6 months & 4.7 & 0.5 & 0 & 17 & 12.5 \\
\hline 12 months & 4.8 & 0.5 & 0 & 13 & 7.8 \\
\hline
\end{tabular}

for a current diagnosis (present in the last month). Classically, it has been difficult to engage fathers and thus to maximize the number of fathers included this study, ${ }^{24}$ we extended the period for paternal recruitment across the first postpartum year. On average, paternal SCIDs were completed at a mean of 20.8 [ standard deviation $(\mathrm{std})=10.0$ ] weeks postpartum. The timing of the paternal diagnosis (lifetime $v s$. current), presence of a paternal diagnosis and the type of diagnosis were examined in relationship to maternal depressive symptom trajectory. Each parent was interviewed individually.

\section{Statistical analysis}

Depression measured by EDPS can be examined as a continuous or dichotomous variable (cutoff of 13).19,20 To capture the full variability of depressive symptoms, EPDS scores were evaluated as a continuous variable. Pearson's correlations were used to examine the relationships between postpartum EPDS scores at the various time points. Probabilities reported are two-tailed and significance is established at $\mathrm{P}<0.05$.

To determine the predictive utility of measures of paternal psychopathology, including timing of psychopathology and type of paternal psychopathology diagnosis on the trajectory of depression scores from 1 month to 12 months postpartum, slopes of depression scores on postpartum age were compared with a mixed effects regression analysis as discussed by Fitzmaurice et al.25 To further investigate the suggestive, though not significant, results of paternal diagnosis timing on maternal on depression score levels from pregnancy to the postpartum period (see Results), mean scores were compared with a repeated measures analysis of variance (Fitzmaurice et al). ${ }^{25}$ These analyses were done with the SAS procedure MIXED. ${ }^{26}$ As there was not a significant effect of paternal lifetime history vs. current diagnosis on trajectory of maternal depressive symptoms (see Results), further analysis included all lifetime and current diagnoses to create an evaluation of paternal lifetime history of mental health disorders on maternal depressive symptoms. In addition, none of the parental demographics collected, including age range, race, education, employment, marital status (Table 2) affected the analysis.
Table 4. Pearson correlation coefficients of Edinburgh Postnatal Depression scores in mothers during postnatal 1,6 , and 12 months. Scores are correlated at all three time points.

\begin{tabular}{lll}
\hline lime points & 1 month 6 months \\
1 months & & \\
6 months & $0.629^{*}$ & \\
\hline 12 months & $0.483^{*}$ & $0.473^{*}$ \\
\hline
\end{tabular}

*Correlation is significant at the 0.01 level.

However, presence of lifetime maternal depressive history (29 out of 64 women) and substance abuse (14 out of 64 women) was controlled for in the following analyses.

\section{Results}

\section{Sample characteristics}

The mean age of mothers was 29.0 years $(s t d=3.5)$ and the mean age of fathers was $30.0(\mathrm{std}=6.0)$. All other maternal and paternal demographics are included in Table 2. Half of the mothers in this study were unemployed, including mothers who chose to be temporarily unemployed after the birth of their child.

\section{Maternal depressive symptom characteristics}

The minimum, maximum and mean EPDS scores at 1, 6 and 12 months postpartum are listed in Table 3. Also listed is the percentage of scores that reached clinical significance of high depressive symptoms, using the EPDS cut-off of $\geq 13$ for major depression. 19,20

\section{Correlation and general trajectory of maternal depressive symptoms}

A correlation analysis was used to evaluate maternal depressive symptoms throughout the first year postpartum. Table 4 contains Pearson correlation coefficients of EPDS scores taken at 1, 6 and 12 months postpartum. EPDS selfreport scores at all time points were significantly intercorrelated (Table 4). 
Effects of timing (lifetime history vs. current diagnosis) of paternal mental illness on maternal depressive symptoms

There was not a significant effect of timing of Axis I paternal diagnosis (lifetime history, $\mathrm{n}=17$, vs. current diagnosis, $\mathrm{n}=14$ ) determined from the SCID on the trajectory of maternal depressive symptoms across the first postpartum year. The mixed effects regression model did not detect a significant slope of maternal depressive symptoms over time postpartum for mothers with partners who received a lifetime paternal diagnosis (slope $=0.50, \mathrm{t}=1.22, \mathrm{df}=59$, $\mathrm{P}=0.23$ ), a current paternal diagnosis (slope $=$ $0.36, \mathrm{t}=-0.94, \mathrm{df}=59, \mathrm{P}=0.35$ ) or did not receive a diagnosis (slope $=-0.36, \mathrm{t}=-1.25, \mathrm{df}=59$, $\mathrm{P}=0.22$; Figure 1 )

There also was not a significant difference between slopes of the groups (Table 5). Group differences at each time point were also analyzed with a repeated measures analysis of variance. There was no significant difference between maternal depressive symptoms between the lifetime and no diagnosis groups at 1 month $(\mathrm{t}=-1.06, \mathrm{P}=0.29), 6$ months $(\mathrm{t}=-$ $0.98, \mathrm{P}=0.33$ ) nor at 12 months postpartum $(\mathrm{t}=-0.13, \mathrm{P}=0.90)$. In addition, there was no significant difference between maternal depression between the current and lifetime diagnosis groups at 1 month $(\mathrm{t}=1.46, \mathrm{P}=0.15)$, at 6 months $(\mathrm{t}=1.11, \mathrm{P}=0.27)$ nor at 12 months postpartum $(\mathrm{t}=0.54 \mathrm{P}=0.59)$. There also was no significant difference between the current and no diagnosis groups at 1 month postpartum $(\mathrm{t}=0.68, \mathrm{P}=0.50)$, at 6 months postpartum $(\mathrm{t}=0.34, \mathrm{P}=0.73)$ nor at 12 months postpartum $(\mathrm{t}=0.54 \mathrm{P}=0.60)$.

\section{Effects of existence and type of paternal mental illness on maternal depressive symptoms}

Many of the fathers had a history of multiple psychiatric diagnoses. To address this situation and maximize the number of fathers within each diagnostic category, the fathers were hierarchically categorized into 3 groups: diagnosis with psychosis $(n=1)$, followed by a mood/anxiety-related diagnosis only $(n=20)$, and lastly a substance abuse-related diagnosis $(n=10)$. Thus, twelve fathers, 2 with a specific phobia, 2 with major depressive disorder, 1 with minor depressive disorder, 1 specific phobia, 1 with bipolar disorder, 1 with specific phobia and generalized anxiety, 1 with major depression and specific phobia, 1 with major depression and social phobia, 1 with major depression and panic disorder, 1 with bipolar, agoraphobia and obsessive compulsive disorder, and 8 fathers had both a mood and substance abuse disorder. These 20 fathers were combined to represent mood/anxiety-related

Table 5. Results of mixed models analysis predicting effects of existence and type of paternal mental illness on maternal depressive symptoms. Mothers with partners with substance abuse exhibited an elevated trajectory of maternal depressive symptoms during the first year postpartum.

\begin{tabular}{|c|c|c|c|c|c|}
\hline & \multicolumn{5}{|c|}{ Timing of paternal diagnosis } \\
\hline & Estimate & SE & df & $\mathrm{T}$ & Sig. \\
\hline Current vs. lifetime & -0.18 & 0.21 & 59 & -0.85 & 0.40 \\
\hline Current $v s$. none & 0.12 & 0.19 & 59 & 0.64 & 0.53 \\
\hline \multirow[t]{2}{*}{ Lifetime vs. none } & 0.30 & 0.18 & 59 & 1.68 & 0.09 \\
\hline & \multicolumn{5}{|c|}{ Paternal diagnosis type } \\
\hline $\begin{array}{l}\text { Substance abuse vs. mood } \\
\text { Substance abuse vs. none } \\
\text { Mood vs. none }\end{array}$ & $\begin{array}{c}0.39 \\
0.36 \\
-0.02\end{array}$ & $\begin{array}{l}0.16 \\
0.15 \\
0.13\end{array}$ & $\begin{array}{l}59 \\
59 \\
59\end{array}$ & $\begin{array}{l}2.37 \\
2.43 \\
1.31\end{array}$ & $\begin{array}{c}0.02^{*} \\
0.02^{*} \\
0.82\end{array}$ \\
\hline
\end{tabular}

*Significant at the $\mathrm{P}<0.05$ level.

diagnoses and the last 10 fathers had diagnoses that consisted of substance abuse only. There was also one father with schizophrenia and agoraphobia, but as he was the only one to exhibit psychosis, he was excluded from the analysis. $48.4 \%$ of fathers met criteria for an Axis I diagnosis.

The mixed effects regression model detected a significant slope of maternal depressive symptoms over time in the postpartum period for mothers with partners who received a paternal substance abuse-related diagnosis (slope $=0.33, \mathrm{t}=1.26, \mathrm{df}=59, \mathrm{P}=0.02$ ), but those who received a paternal mood-related diagnosis (slope $=0.20, \mathrm{t}=0.87, \mathrm{df}=59, \mathrm{P}=0.39$ ), nor for mothers whose partners who did not receive a diagnosis (slope $=-0.03, \mathrm{t}=-0.43$, $\mathrm{df}=59, \mathrm{P}=0.79$; Figure 2). In addition, a significant difference was detected between the slopes of these groups, such that mothers with partners who received a paternal substance abuse-related diagnosis had an increased trajectory of depressive symptoms relative to both those with a mood-related diagnosis $(\mathrm{P}=0.02)$ and those who without no diagnosis $(\mathrm{P}=0.02$; Table 5).

\section{Discussion}

The current study evaluated the relationship between maternal depressive symptoms and paternal risk for psychopathology, independent of mother's own depressive history. We expected that mothers with partners at risk for mental illness would have more severe and prolonged maternal depression when compared with mothers with partners not at risk. While maternal depressive symptoms were correlated throughout the first twelve months postpartum, father's mental health moderated the course of these symptoms. Separate from maternal history of depression, a paternal substance abuse-related Axis I diagnosis was associated with augmented maternal depres- sive symptoms, relative to a paternal moodrelated diagnosis or no paternal diagnosis. However, the timing of paternal diagnosis (lifetime $v s$. current) did not affect maternal depressive symptom trajectory. This study goes beyond previous work to evaluate paternal mood and substance abuse disorders in the same population and strongly identifies paternal substance abuse-related disorder, a largely overlooked predictor in, as an important risk factor for worsening maternal depressive symptoms over the first year postpartum.

The psychiatric lifetime history of the father may be a critical piece in the regulation of maternal depression. According to father lifetime psychiatric interviews, $48.4 \%$ of fathers had a lifetime history of mental illness, replicating previous research suggesting that $\sim 50 \%$ of all Americans will meet criteria for an Axis I diagnosis during their lives. ${ }^{27}$ While the history of a paternal psychiatric condition relative to current diagnosis, though not significant, was suggestive of a negative effect on depressive symptoms in mothers, the specific diagnosis was important in driving this relationship. Specifically, mothers (regardless of their own depression history) with partners with history of a substance abuse-related diagnosis had a progressive increase of depressive symptoms relative to mothers with partners with a mood-related diagnosis or mothers with partners without an Axis I diagnosis. This suggests that in the current sample, mothers' course of depressive symptoms worsened more so with paternal substance abuse symptoms. Paternal substance abuse is associated with a father's guilt and shame about has failure to fulfill his parental societal role. ${ }^{28,29}$ These feelings, coupled with substance abuse and societal norms, may cause fathers to avoid involvement with their children, 6,14 creating a family with an absent father. Thus, fathers with a substance abuse-related history may not provide the mother with social support, a strong predictor of maternal depression. 13 Thus, this study and others highlight the importance of 
the negative effects of substance abuse on maternal mental health throughout the first year postpartum.

It is unclear why substance abuse disorders may worsen a mother's depressive symptoms rather than a mood-related disorder. Substance abuse disorders have negative effects on family functioning and can have devastating financial and legal consequences for parents. ${ }^{30,31}$ Thus, substance abuse symptoms are detrimental to overall maternal mental health. In addition, there is a strong link between alcohol dependence and depression and research has shown that men use substance abuse to mask psychiatric illness or may experience substance-induced mood disorders. $^{32-34}$ Thus, substance abuse may increase the risk that men's psychopathology may go undiagnosed and untreated. Substance abuse has also been related to various personality disorders in men as well as to depression and suicide. 35 Though not measured with the SCID which was used in the current study to evaluate paternal mental health, it is possible that personality disorders may account for the adverse effects of father psychopathology on maternal depressive symptoms. Measuring paternal personality disorders in conjunction with substance abuse in future studies would elucidate this question. However, based on our results of the detrimental effect of substance abuse on maternal depressive symptoms; the need to evaluate paternal substance abuse history when assessing maternal depression is evident.

Paternal and maternal psychopathologies are often intertwined. While paternal substance abuse alone can predict poor child developmental outcomes, ${ }^{28}$ the interaction between maternal depression and father substance abuse can also interact to predict the development of depression and externalizing behavior problems in offspring.6,15 This interaction between maternal depression and paternal substance abuse has been associated with high levels of family stress relative to each parental disorder alone. ${ }^{6}$ Fathers with substance abuse have specific characteristics that may contribute to this elevated level of stress. They have been found to father more children and have fewer resources relative to fathers without this disorder.28,36,37 In addition, it is likely that fathers and mothers with substance abuse are subject to assortative mating. The high rates between partners with cooccurring substance abuse disorders have been well documented.38,39 Thirteen of the 64 of mothers in the current study met criteria for a substance abuse diagnosis, at a rate much lower than that of the fathers who met diagnosis (20.3\% vs. $48.4 \%)$. Of those mothers who obtained a substance abuse diagnosis, almost half also had partners also with a substance abuse diagnosis ( 7 out of 13 women).
Concomitant substance abuse diagnoses amongst couples likely have an effect on maternal depression. Partners with co-occurring substance abuse spend more time involved in drug use, exhibit decreases in relationship satisfaction and overall demonstrate poor psychological functioning. 38,40 These changes are particularly noteworthy as the relationship between a mother and her partner is a strong predictors of maternal depression.1,12,41 It may be that paternal and maternal substance abuse are contemporaneously affecting maternal depressive by lowering healthy relationship functioning and/or increasing codependence in substance abuse related activities. However, even when the cofounding variable of maternal substance abuse is accounted for in our analysis, paternal substance abuse is still a significant predictor of maternal depressive symptom trajectory. Our results extend previous research by demonstrating that paternal substance abuse alone can directly have a negative effect on maternal depression.

In the current study, women with partners with a substance abuse disorder had an increasing maternal depressive symptom trajectory across the first year postpartum. However, due to small numbers of lifetime and current subgroups (16 vs. 14, respectively), we were not able to analyze each diagnosis type (mood $v s$. substance abuse) by timing of diagnosis. It is possible that specific types of current paternal mental health diagnoses might be more relevant to maternal depressive symptoms than vulnerability or that the assessments weren't completely independent of maternal functioning overtime. One way to address this limitation would be to collect maternal and paternal mental data at the same time points. Although this was not the case, the current study did identify important results pointing to the negative consequences of paternal mental health history on maternal functioning. In addition, while $48.4 \%$ of the fathers who participated exhibited history of psychopathology, we only had only 64 fathers, representing a limited range of diagnosis. In addition, while employment history was not associated with psychopathology and the majority of fathers in this study were unemployed. This may reflect an overall lower functioning population which may contribute to the elevated levels of psychopathology reported in this study. As a next step, a larger sample size of greater psychosocial diversity should be obtained so that associations of specific paternal psychopathologies (depression vs. anxiety vs. substance abuse) and maternal depressive symptom trajectories can be reliably tested. However, this data suggests that fathers who have developed a substance-abuse related disorder at one point in their lives negatively influence maternal postpartum depression beyond that of the initial perinatal period.

While most parental depression research focuses on mothers, our findings support a role for paternal involvement. Previous research indicates that paternal involvement may offset some of the well known negative effects maternal depression on child outcomes. Fathers without mental health disorders can buffer the impacts of maternal depression on infant outcomes. ${ }^{42,43}$ Increased quantity of father-child interactions is also associated with fewer behavior problems in children and better school performance. ${ }^{44,45}$ However, the quality of these interactions must be high to overcome the negative effects of a depressed mother relationship as maternal depression is highly linked to father-infant interactions. ${ }^{44,46}$ Due to the possible buffering effects of positive father involvement on the depressed mother-child pair, evaluating how paternal risk for psychopathology, especially parental substance abuse, affects maternal depressive symptoms should be further evaluated.

\section{Conclusions}

In summary, our data support the notion that providers may benefit from taking a closer look at father involvement and paternal mental health status. Particularly it highlights the need to look beyond of women's depressive past at the lifetime history of paternal substance abuse of her partner when evaluating and treating maternal depression. By understanding the effects of paternal risk for substance-abuse on the trajectory of maternal depressive symptoms, valuable empirical data can be gathered to support early intervention of both paternal and maternal psychopathologies that could potentially have positive effects on healthy child development.

\section{References}

1. O'Hara M, Swain AM. Rates and risk of postpartum depression-a meta-analysis. Int Rev Psychiatr 1996;8:37-55.

2. Murray L, Cooper P. Effects of postnatal depression on infant development. Arch Dis Child 1997;77:99-101.

3. Bloch M, Daly RC, Rubinow DR. Endocrine factors in the etiology of postpartum depression. Compr Psychiat 2003;44:23446.

4. Beck CT. Postpartum Depression: A Metasynthesis. Qual Health Res 2002; 12:453-72.

5. Chew-Graham C, Sharp D, Chamberlain E, et al. Disclosure of symptoms of postnatal depression, the perspectives of health pro- 
fessionals and women: a qualitative study. BMC Fam Pract 2009;10:7.

6. Brennan PA, Hammen C, Katz AR, Le Brocque RM. Maternal depression, paternal psychopathology, and adolescent diagnostic outcomes. J Consult Clin Psychol 2002;70:1075-85.

7. Matthey S, Barnett B, Howie P, Kavanagh DJ. Diagnosing postpartum depression in mothers and fathers: whatever happened to anxiety? J Affect Disord 2003;74:139-47.

8. Merikangas KR, Prusoff BA, Weissman MM. Parental concordance for affective disorders: psychopathology in offspring. $\mathrm{J}$ Affect Disord 1988;15:279-90.

9. Wandersman L, Wandersman A, Kahn S. Social support in the transition to parenthood. J Community Psychol 2006;8:332-42.

10. George LK, Blazer DG, Hughes DC, Fowler N. Social support and the outcome of major depression. Br J Psychiatry 1989; 154:478-85.

11. Goering PN, Lancee WJ, Freeman SJJ. Marital support and recovery from depression. Br J Psychiatry 1992;160:76-82.

12. Blanchard A, Hodgson J, Gunn W, et al. Understanding social support and the couple's relationship among women with depressive symptoms in pregnancy. Issues Ment Health Nurs 2009;30:764-76.

13. Seyfried L, Marcus S. Postpartum mood disorders. Int Rev Psychiatr 2003;15:23142.

14. Furstenberg FF. Fatherhood: contemporary theory, research and social policy. Thousand Oaks, CA: Sage Publications, Inc.; 1995.

15. Ramchandani P, Psychogiou L. Paternal psychiatric disorders and children's psychosocial development. Lancet 2009;374:646-53.

16. Goodman SH, Brogan D, Lynch ME, Fielding B. Social and emotional competence in children of depressed mothers. Child Dev 2009;64:516-31.

17. Weissman MM, Prusoff BA, Gammon GD, et al. Psychopathology in the children (ages 6-18) of depressed and normal parents. J Am Acad Child Psychiatry 1984;23:78-84.

18. Kim-Cohen J, Moffitt TE, Taylor A, et al. Maternal depression and children's antisocial behavior: nature and nurture effects. Arch Gen Psychiatry 2005;62:173-81.

19. Cox J, Holden J, Sagovsky R. Detection of postnatal depression. Development of the 10-item Edinburgh Postnatal Depression Scale. Br J Psychiatry 1987;150:782-6.

20. Cox JL, Murray D, Chapman G. A controlled study of the onset, duration and prevalence of postnatal depression. Br J Psychiatry 1993;163:27-31.

21. Murray D, Cox JL. Screening for depression during pregnancy with the edinburgh depression scale (EDDS). J Reprod Infant Psyc 1990;8:99-107.

22. Alfonso D, De AK, Horowitz JA, Mayberrry LJ. An international study exploring levels of postpartum depressive symptomatology. J Psychosom Res 2000;49:207-16.

23. Dennis CL. Can we identify mothers at risk for postpartum depression in the immediate postpartum period using the Edinburgh Postnatal Depression Scale? J Affect Disord 2004;78:163-9.

24. Phares V. Where's poppa?: the relative lack of attention to the role of fathers in child and adolescent psychopathology. Am J Psychol 1992;47:656-64.

25. Fitzmaurice GM, Laird NM, Ware JH. Applied longitudial analysis. Hoboken: John Wiley \& Sons; 2004.

26. SAS Institute I. SAS/STAT 9.2. Available from: http://support.sas.com/documentation/cdl/en/statugintroduction/61750/PDF/ default/statugintroduction.pdf.

27. Kessler RC, Berglund P, Demler 0, et al. Lifetime prevalence and age-of-onset distributions of DSM-IV disorders in the national comorbidity survey replication. Arch Gen Psychiatry 2005;62:593-602.

28. McMahon TJ, Rounsaville BJ. Substance abuse and fathering: adding poppa to the research agenda. Addiction 2002;97:110915.

29. Twomey JE. Partners of perinatal substance users: forgotten, failing or fit to father? Am J Orthopsychiat 2007;77:56372 .

30. Chassin L, Pitts SC, DeLucia C, Todd M. A longitudinal study of children of alcoholics: Predicting young adult substance use disorers, anxiety and depression. J Abnorm Psychol 1993;108:106-19.

31. Wolock I, Magura S. Parental substance abuse as a predictor of child maltreatment re-reports. Child Abuse Neglect 1996;20: 1183-93.

32. Davidson KM, Ritson EB. The relationship between alcohol dependence and depression. Alcohol 1993;28:147-55.

33. Kessler RC, McGonagle KA, Zhao S, et al. Lifetime and 12-month prevalence of DSM-III-R psychiatric disorders in the United States. Results from the National Comorbidity Survey. Arch Gen Psychiatry 1994;51:8-19.

34. Cooper ML, Frone MR, Russell M, et al. Gender, stress, coping, and alcohol use. Gender and alcohol: individual and social perspectives. New Brunswick, NJ: Rutgers Center of Alcohol Studies; 1997. pp 199224.

35. Samuels J. Personality disorders: epidemiology and public health issues. Int Rev Psychiatr 2011;23:223-33.

36. McMahon T, Luthar SS, Rounsaville BJ. Finding poppa: a comparative study of fathers enrolled in methadone maintenance treatment. Drug Alcohol Depen 2001;63:102.

37. McMahon TJ, Winkel JD, Luthar SS, Rounsaville BJ. Looking for poppa: parenting status of men versus women seeking drug abuse treatment. Am J Drug Alcohol Ab 2005;31:79-91.

38. Low N, Cui L, Merikangas KR. Spousal concordance for substance use and anxiety disorders. J Psychiatr Res 2007;41:94251.

39. Vanyukov MM, Neale MC, Moss HB, Tarter RE. Mating assortment and the liability to substance abuse. Drug Alcohol Depen 1996;42:1-10.

40. Fals-Stewart W, Birchler GR, O'Farrell TJ. Drug-abusing patients and their intimate partners: Dyadic adjustment, relationship stability, and substance use. J Abnorm Psychol 1999;108:11-23.

41. Feeney J, Alexander R, Noller P, Hohaus L. Attachment insecurity, depression, and the transition to parenthood. Pers Relationships 2003;10:475-93.

42. Goodman SH, Gotlib IH. Risk for psychopathology in the children of depressed mothers: a developmental model for understanding mechanisms of transmission. Psychol Rev 1999;106:458-90.

43. Tannenbaum L, Forehand R. Maternal depressive mood: the role of the father in preventing adolescent problem behaviors. Behav Res Ther 1994;32:321-5.

44. Chang JJ, Halpern CT, Kaufman JS. Maternal depressive symptoms, father's involvement, and the trajectories of child problem behaviors in a US national sample. Arch Pediatr Adolesc Med 2007; 161:697-703.

45. Mezulis AH, Hyde JS, Clark R. Father involvement moderates the effect of maternal depression during a child's infancy on child behavior problems in kindergarten. J Fam Psychol 2004;18:57588.

46. Goodman JH. Influences of maternal postpartum depression on fathers and on father-infant interaction. Inf Mental Hlth J 2008;29:624-42. 